\title{
Philosophy of science and black swan
}

\author{
Tayfun Hakan $^{1,2}$ (D)
}

Received: 2 December 2020 / Accepted: 7 December 2020 / Published online: 6 January 2021

(C) The Author(s), under exclusive licence to Springer-Verlag GmbH, DE part of Springer Nature 2021

\section{Philosophy of science}

Science produces knowledge about the phenomena it studies and explains the facts that it thus has come to know. Scientists use physical procedures of observation, experimentation, and measurement, together with intellectual approaches like inductive and deductive inference to craft scientific hypotheses to achieve their purpose. The philosophy of science studies the observational and/or experimental sciences; it analyzes their procedures and observations to produce a logical explanation of scientific practices with regard to the facts it studies [3].

\section{Francis Bacon, producing scientific knowledge}

Scientific laws are hypotheses about how nature and the universe work that have been consolidated or reinforced to the point that they are considered to be in effect without constraint by time or space; they declare things always occur the same way under the same circumstances.

Francis Bacon, an English philosopher who lived from 1561 to 1626 , thought that induction and inductive reasoning were the basis of all scientific knowledge of nature (Fig. 1: cover figure, lower left). In his Novum Organum, he argued that knowledge would be scientific if it was derived in the right way; a new inductive method, involving observation of particular facts, should be used for generating such scientific truths as that all swans are white [4].

Tayfun Hakan

tayfunhakan@yahoo.com

1 Neurosurgery Clinic, Fatih Sultan Mehmet Training and Research Hospital, Istanbul, Turkey

2 Fatih Sultan Mehmet Eğitim ve Araştırma Hastanesi, Beyin ve Sinir Cerrahisi Kliniği Hastane Sokak, No:1/8 İçerenköy - Atașehir, 34752 Istanbul, Turkey

\section{Verifiability}

Verifiability relates to empirically verifiable statements of knowledge: every meaningful statement must be testable and/or verifiable, regardless of whether it is true or false [6]. When you see a swan that is white, you can say "this is a swan" and "this is white," without committing to any sense of true or false in the larger analysis. To make the statement "all swans are white," you must observe all swans, such that everything is verified by observation.

\section{Black swan}

The question of the white swan issue derives from the secondcentury Roman poet Juvenal's Satire VI. On this telling, black swans were presumed not to exist, and the phrase "rara avis in terris nigroque simillima cygno" (a rare bird in the lands and very much like a black swan") was common [1]. Millions of swans were observed for centuries, and all of them were white without exception; thus, following inductive reasoning, one can conclude that all swans are white was a universal truth. This conclusion was valid until January 1667, when the Dutch explorer Willem de Vlamingh saw black swans in Australia (Fig. 1: cover figure, upper) [2]. His observation of a black swan falsified the hypothesis that all swans are white and undercut Bacon's inductive approach to creating scientific knowledge.

\section{Karl Raimund Popper, falsifiability}

The philosopher of science Karl Popper introduced the idea of falsifiability in his Logic der Forschung in 1934, which was revised and translated into English as The Logic of Scientific Discovery in 1957, published in 1959 (Fig. 1: cover figure, lower right). This philosophical approach places falsifiability as the central factor for a statement, theory, or hypothesis for disproving it with evidence, and it was suggested by Popper for use 


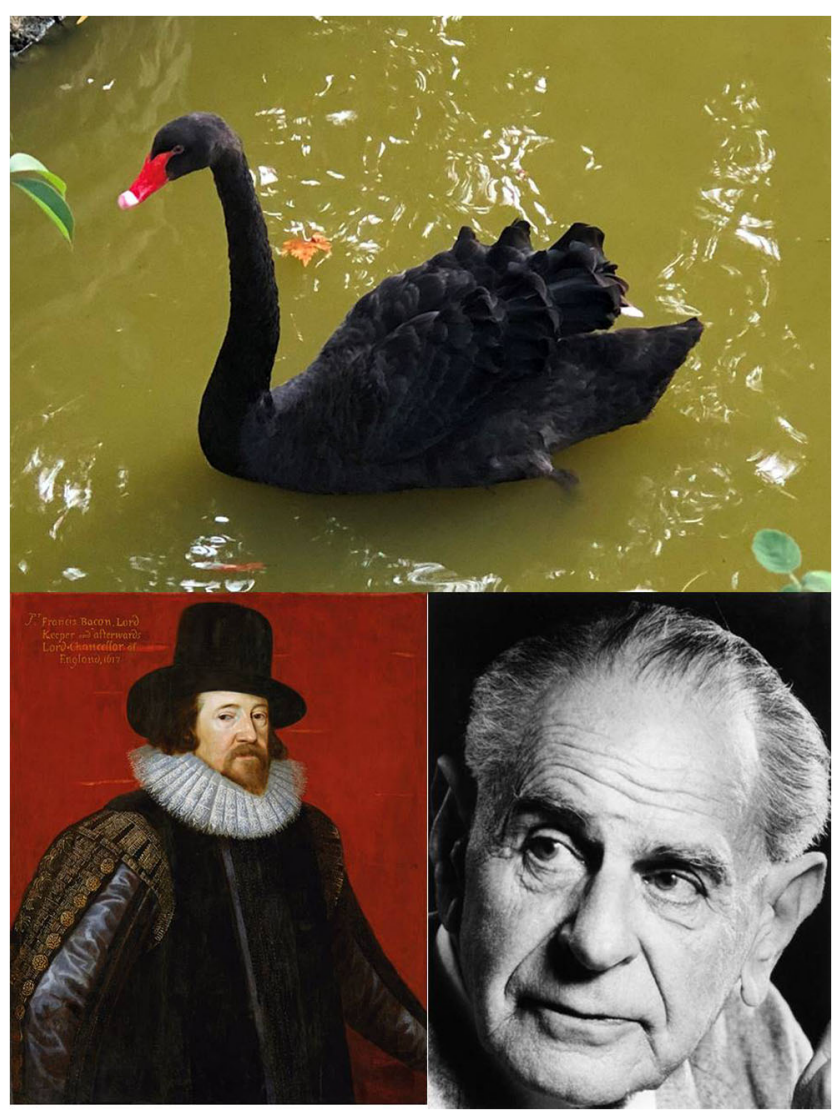

Fig. 1 Cover figure: Black swan. Photo by Tayfun Hakan. Degirmen Ciftlik, Kuşadası/Aydın/Turkey (upper). Francis Bacon. https:// commons.wikimedia.org/wiki/File:Somer_Francis_Bacon.jpg (lower left). Karl Raimund Popper. https://en.wikipedia.org/wiki/Karl_ Popper\#/media/File:Karl_Popper.jpg (lower right)

as a criterion that could demarcate science from nonscience [5].

Popper considered that when empirical sciences used inductive methods, the logic of scientific discovery is identical with inductive logic. It is possible for an inductive inference to pass from singular statements that contain no variables, such as accounts of the results of observations or experiments, to universal statements, like hypotheses or theories. From a logical point of view, inferring universal statements from singular statements may always produce false results. "No matter how many instances of white swans we may have observed, this does not justify the conclusion that all swans are white." Here, falsifiability is what drives science forward. The value of a hypothesis or a theory is not how far it has been verified but how far it can resist falsification. A thesis is true only if it cannot be falsified.

\section{Neurosurgical considerations}

Observation is an important method of pursuing scientific knowledge, and it must be strong, reliable, and objective if it is to be accepted as successful. Relying on our observations, experiences, research, and correlative evidence, we can make reasonable assumptions that can be called propositions or hypotheses. We should always remember, however, that an observation or the result of an experiment is in the first place only a singular statement, not a universal one.

In neurosurgical practice, we observe and experience many things, reach opinions, and produce results. We commonly share these in daily conversations, conferences, articles, and books. Personal communications and unpublished works are also used in the text of published research articles by wellknown scientific journals with high-impact factors. Sharing an experience can be a very positive means of inspiring, guiding, or exacting lessons, but it can be very dangerous for the reader, who may consider these discourses to be unquestionably true. "I have never seen a late slippage of an aneurysm clip in the postoperative period" is an excellent example of a nonscientific expression produced by a reviewer.

The lessons learned from each case are priceless for a scientist, but we should remember that experience of the overwhelming majority of cases never gives us the right to recite long dogmatic speeches.

We should be very careful while using observational interferences in scientific articles as "a golden standard," or describing them in any of the following ways: "most effective," "the only determining factor," "the best approach," "it is ideal to study," and "does not result"; these determinations are likely to change over time. We should also avoid using ambiguous, variable, and/or subjective concepts like "maximal safe resection," "supra maximal resection," "most extensive resection," "minimally invasive," "expert neurosurgeon," or "less experienced neurosurgeon."

Objectivity, testability, and universality should always be our fundamental and indispensable guides; we should never forget that a black swan can always appear.

The black swan metaphor is a very typical trope used to show the fragility of any thought system.

Acknowledgments Preparation for publication of this article is partly supported by Turkish Neurosurgical Society.

\section{Compliance with ethical standards}

Conflict of interest The author states that there is no conflict of interest.

\section{References}

1. Black swan theory. [Wikipedia web site]. Available at: https://en. wikipedia.org/wiki/Black swan theory\#cite note-etruscan swan-3. Accessed 25 Nov 2020

2. Flag of Western Australia. [Online Encyclopaedia Britannica web site]. Available at: https://www.britannica.com/topic/flag-ofWestern-Australia\#ref712065. Accessed 15 Nov 2020 
3. Hakan T (2020) A brief look from the neurosurgical perspective into the philosophy of science. Turk Neurosurg. https://doi.org/10.5137/ 1019-5149.JTN.31770-20.2 Online ahead of print

4. Mumford S (2008) Metaphysics. In: Phillos, Curd (eds) The Routledge Companion to Philosophy of Science. Taylor \& Francis, Abington, p 27

5. Popper KR (1959) The logic of scientific discovery. Hutchinson \& Co., London
6. Rosenberg A (2005) Philosophy of science: a contemporary introduction, 2nd edn. Routledge, New York, p 23

Publisher's note Springer Nature remains neutral with regard to jurisdictional claims in published maps and institutional affiliations. 